\title{
A escuta de crianças e adolescentes nos processos de crimes sexuais
}

\author{
Meanings attributed by children and adolescents \\ to court cases concerning sexual crimes
}

Lygia Maria Pereira da Silva ${ }^{1}$

Maria das Graças de Carvalho Ferriani ${ }^{2}$

Maria Aparecida Beserra ${ }^{1}$

Eliana Mendes de Souza Teixeira Roque ${ }^{3}$

Diene Monique Carlos ${ }^{2}$

${ }^{1}$ Faculdade de Enfermagem Nossa Senhora das Graças, Universidade de Pernambuco. R. Amóbio Marques 310, Santo Amaro. 50.100-130 Recife PE. lygia.silva@upe.br

${ }^{2}$ Escola de Enfermagem de Ribeirão Preto, Universidade de São Paulo. ${ }^{3}$ Tribunal de Justiça do Estado de São Paulo.

\begin{abstract}
This paper addresses the perception of members of the judiciary regarding the introductory deposition. The concept of comprehensive protection was used as a theoretical benchmark. It involves qualitative research, in which the semi-structured interview enabled the production of data, organized according to the content analysis technique, resulting in the following themes: production of evidence; protection; and challenges/needs. A positive perception of the interview was expressed in all themes. It became clear, however, that the culture observed in the judiciary arises as an obstacle to conducting the introductory deposition, since it is necessary to adapt the institution in order to apply the methodology. The enhancement of the physical infrastructure and training of the judiciary clerks are challenges to be overcome for the implementation of the interview as one of the court case procedures involving children and adolescents who are the victims or witnesses of violence.
\end{abstract}

Key words Child, Adolescent, Mental health, Child and adolescent advocacy
Resumo Este artigo aborda a percepção de membros do Poder Judiciário acerca da entrevista do depoimento acolhedor. Utilizou-se como referencial teórico o conceito de proteção integral. Trata-se de pesquisa qualitativa, em que a entrevista semiestruturada possibilitou a produção dos dados, organizados conforme a técnica de análise de conteúdo, resultando nas seguintes temáticas: produção de provas; proteção; e desafios/necessidades. Expressou-se em todos os temas uma percepção positiva da entrevista. Evidenciou-se, no entanto, que a cultura observada no Poder Judiciário se apresenta como obstáculo à realização da entrevista do depoimento acolhedor, sendo necessário adaptar a instituição para aplicar a metodologia. O aprimoramento da estrutura física e a capacitação dos serventuários da Justiça são desafios a ser enfrentados para a implementação da entrevista como um dos procedimentos dos processos judiciais que envolvem crianças e adolescentes vitimas ou testemunhas de violência.

Palavras-chave Criança, Adolescente, Saúde Mental, Defesa da criança e do adolescente 


\section{Introdução}

A violência contra a criança e o adolescente está no cotidiano dos profissionais que atuam junto a esse grupo etário, e o Poder Judiciário mostrase como a última instância ${ }^{1}$, tendo papel importante na imposição do limite para os autores desse tipo de violência ${ }^{2-4}$.

A violência sexual cometida contra crianças e adolescentes pode causar danos que repercutem de modo global na saúde das vítimas. As lesões físicas, decorrentes da violência praticada, envolvem lacerações anogenitais, doenças sexualmente transmissíveis, gravidez etc., e, com frequência, demandam vários tratamentos. Entretanto, dependendo da forma da violência sexual ou do tempo decorrido do evento até o exame, na maioria dos casos, o exame pericial não resulta em prova material ${ }^{1-5}$.

Por outro lado, os danos psíquicos ocasionados por essa forma de violência interferem no desenvolvimento psicossocial e na estruturação da personalidade da vítima, podendo repercutir ao longo de sua vida. Ainda, a violência sexual tem como característica fundamental o segredo, mantido por diversos meios. Por isso, torna-se necessário valorizar a subjetividade, possibilitando a revelação da experiência vivida por meio de procedimentos técnicos variados que forneçam provas que contribuam para esclarecer os fatos ${ }^{2,5}$.

Reconhecida como meio importante para produção de provas, a audiência, em geral, é considerada um procedimento revitimizante, sobre o qual os depoentes expressam medo e ansiedade, tendo, ainda, pouca compreensão sobre o processo judicial $^{6}$. Além das dificuldades próprias da vítima relatar uma situação traumática, os operadores do direito revelam dificuldades em lidar com o tema, seja pelo despreparo técnico para colher o depoimento da criança, por suas características peculiares, seja pelas dificuldades que a abordagem da violência sexual oferece ${ }^{1,2,5}$. Desse modo, o estudo do tema permite maior aproximação ao problema do depoimento das crianças e adolescentes nos processos judiciais, levando a considerá-lo um problema de pesquisa no campo da saúdee especificamente da saúde mental.

Diante dessas colocações e buscando equalizar as necessidades de garantir a precisão do testemunho e, ao mesmo tempo, evitar a revitimização, em vários países têm sido implantadas metodologias para a tomada do depoimento das crianças e dos adolescentes envolvidos em processos judiciais, seja como vítimas, seja como testemunhas ${ }^{6,7}$.
Estudos internacionais possibilitam constatar que o tema da escuta da criança em juízo tem sido abundantemente abordado em países europeus e norte-americanos. $\mathrm{Na}$ atualidade, os estudos recomendam e avaliam a utilização de protocolos e o treinamento de profissionais para a entrevista forense $\mathrm{e}^{8-12}$.

No Brasil, pesquisas sobre o tema têm sido mais recentes. Vários estudos mostram a importância de investimentos urgentes na modificação dessa prática com mudanças nas leis e criação de estratégias que minimizem os danos da abordagem realizada nos processos judiciais, de modo a oferecer um atendimento com base nos princípios da proteção integral ${ }^{5,13-16}$.

A partir da criação da metodologia do depoimento sem dano (DSD), a tomada do depoimento das crianças e adolescentes tem tido repercussão em várias instituições. O projeto DSD principiou em 2003, por iniciativa do Tribunal de Justiça do Rio Grande do Sul (TJRS), na cidade de Porto Alegre, sendo normatizado em 2004 nos procedimentos desse tribunal. O projeto original objetiva a mitigação do dano durante a produção de provas em processos judiciais nos quais a criança ou o adolescente é vítima ou testemunha ${ }^{7}$.

No estado de Pernambuco, o depoimento especial para crianças e adolescentes foi implantado sob a Portaria $n^{\circ} 45$, em junho de $2010^{17}$, que criou no âmbito do Tribunal de Justiça de Pernambuco (TJPE) a Central de Depoimento Acolhedor de Crianças e Adolescentes Vítimas ou Testemunhas de Violência ${ }^{18}$. Em 2010, o Conselho Nacional de Justiça (CNJ) recomendou aos tribunais a criação de serviços especializados para a escuta de crianças e adolescentes nos processos judiciais. as condições em que o depoimento especial deve ocorrer, considerando o ambiente, a tecnologia a ser utilizada e a capacitação apropriada aos participantes da escuta judicial ${ }^{19}$. Desde então, os estados do Rio Grande do Sul, Pernambuco, Espírito Santo, Sergipe, Goiás, Acre, São Paulo, Maranhão, Rio Grande do Norte e Mato Grosso, além do Distrito Federal, adotam o depoimento especial ${ }^{16}$.

Mediante o quadro descrito, questiona-se se a implementação da referida prática contribui para minimizar a revitimização na audiência, se o depoimento colhido com o auxílio da metodologia proporciona as informações necessárias aos processos judiciais. Por isso, buscamos sintetizar as inquietações em um questionamento: Como os membros do TJPE envolvidos na metodologia do depoimento acolhedor percebem a referida prática? 
A importância deste estudo justifica-se pelos procedimentos que evitam a revitimização e previnem danos à saúde. Além disso, o desenvolvimento de técnicas de entrevista pode propiciar uma contribuição que ultrapasse os limites dos procedimentos judiciais, subsidiando a abordagem das crianças e adolescentes em outras áreas, inclusive a da saúde.

Pretende-se neste estudo proceder à análise da metodologia do DA à luz do conceito da proteção integral. O princípio da proteção integral é derivado da Declaração Universal dos Direitos da Criança, assinada em 1989 e consagrada na Convenção das Nações Unidas sobre os Direitos da Criança e encontra-se previsto no Estatuto da Criança e do Adolescente (ECA) - Lei n. 8.069, de 13 de julho de 1990. Nesta lei, as crianças e adolescentes são consideradas em sua condição de pessoa em desenvolvimento e devem ter suas necessidades atendidas com prioridade absoluta ${ }^{20}$.

O princípio da proteção integral "afirma o valor intrínseco da criança como ser humano; a necessidade de especial respeito à sua condição de pessoa em desenvolvimento; o valor prospectivo da infância e da juventude [...]"21. Ao estabelecer a responsabilidade solidária da família, da sociedade e do Estado pela proteção da criança e do adolescente, o ECA buscou estabelecer garantias por meio da efetivação dos direitos a eles conferidos.

Considerando que a implantação das leis baseadas no paradigma da proteção integral é marcada por avanços e retrocessos, entendemos que provavelmente se encontrem nas práticas dos sujeitos dificuldades para concretizar a implementação do DA e sedimentá-lo como procedimento do processo judicial, haja vista ser o Poder Judiciário uma instituição pautada na tradição e no formalismo. Partindo desse pressuposto, o estudo objetivou analisar a percepção de membros do Poder Judiciário acerca da entrevista do depoimento acolhedor.

\section{Método}

Recorreu-se à abordagem qualitativa, utilizando a análise de conteúdo com o intuito de compreender a percepção de membros do Poder Judiciário acerca da entrevista do depoimento acolhedor.

O campo do estudo foi a Central de Depoimento Acolhedor de Crianças e Adolescentes Vítimas ou Testemunhas de Violência do Tribunal de Justiça de Pernambuco. Essa Central foi constituída por 15 profissionais do quadro efetivo do TJPE, com a atribuição de tomar depoimento nos processos judiciais das Varas de Crimes contra Crianças e Adolescentes, Varas de Família e Varas da Infância e Juventude.

A Central de Depoimento Acolhedor situa-se no Centro Integrado da Criança e do Adolescente (CICA), um complexo destinado ao atendimento desses grupos etários, como preconiza o ECA. Sua instalação envolveu a instalação de uma sala para essa finalidade, a qualificação da equipe para o enfrentamento da violência contra crianças e adolescentes, e o treinamento específico em técnicas de entrevista investigativa, parte do Projeto Culturas Não Revitimizantes: Reflexão e Socialização de Metodologias Alternativas para Inquirir Crianças e Adolescentes em Processos Judiciais, do Governo Federal em parceria com a organização Childhood Brasil.

Os sujeitos do estudo foram 10 membros do Poder Judiciário que atuam na Central de Depoimento Acolhedor e o critério de inclusão foi terem realizado a entrevista de acordo com a metodologia do depoimento acolhedor.

A coleta de dados foi realizada por meio de entrevistas semiestruturadas, com a utilização de um roteiro de perguntas elaborado previamente. As seguintes questões foram colocadas aos sujeitos: O que o(a) senhor(a) entende como objetivos da entrevista do depoimento acolhedor? $\mathrm{O}(\mathrm{a})$ senhor(a) considera que essa entrevista alcança plenamente os objetivos para os quais foi implantada? $\mathrm{O}$ (a) senhor(a) entende que a prática dessa entrevista precisa melhorar? Como? Neste estudo se buscou responder à questão de como os sujeitos percebem a entrevista do DA.

A análise dos dados foi baseada na técnica de análise de conteúdo, em sua modalidade temática. "A técnica de análise temática consiste em descobrir os núcleos de sentido que compõem a comunicação e cuja presença ou frequência de aparição podem significar alguma coisa para o objetivo analítico escolhido"22. A operacionalização se deu a partir de uma leitura de aproximação das falas transcritas, quando se identificou seus componentes e sua estrutura. Em seguida, foi realizada a análise de conteúdo, quando foram identificados os temas em questão. O passo seguinte foi delimitar os núcleos de sentido e suas categorias. Por fim, na fase interpretativa, as informações mais pertinentes foram analisadas de acordo com o quadro teórico proposto.

Este estudo respeitou os princípios éticos da pesquisa com seres humanos, estabelecidos pelo Conselho Nacional de Saúde, por meio da Resolução no $196 / 96^{23}$, e foi aprovado pelo Comitê de Ética da Universidade de Pernambuco. 


\section{Resultados e discussão}

\section{Caracterização dos sujeitos}

Os sujeitos do estudo tinham idade entre 28 e 49 anos, sendo 8 do sexo feminino e 2 do sexo masculino. Todos os sujeitos possuíam curso superior completo ( 1 psicólogo, 2 assistentes sociais, 1 bacharel em letras e 6 pedagogos), 1 cursou somente graduação, 6 cursaram especialização, 1 cursou mestrado. O tempo de atuação no TJPE variou de 2 a 19 anos e, quanto ao cargo ocupado, 7 eram técnicos judiciários e 3 analistas judiciários. Todos participaram de cursos, palestras e congressos sobre o depoimento especial.

\section{As categorias}

Dos discursos dos sujeitos surgiram os seguintes temas: produção de provas; proteção; e desafios/necessidades.

\section{Produção de provas}

Os sujeitos percebem na entrevista do DA o objetivo de produzir provas. Tal percepção é demonstrada inicialmente por meio da comparação com o depoimento tradicional, utilizado na maior parte do país:

A criança era ouvida de forma invasiva, desrespeitosa, e o relato dela saía frouxo, inconsistente. Isso possibilitava que o relato fosse invalidado e o culpado fosse inocentado por falta de provas. (S 08)

No depoimento tradicional, a criança ou o adolescente é colocada diante do juiz, do promotor, do agressor e do seu defensor e do embate entre a promotoria e a defesa. Em muitas audiências, o juiz de direito faz perguntas diretas sobre o fato e, com frequência, a palavra da criança é confrontada com a do agressor. Muitas vezes, a criança não fala, porém, mesmo ao falar, seu relato é invalidado, desacreditado, sendo considerado infantil e fantasioso ${ }^{14,21}$

O depoimento especial está previsto no Código de Processo Penal (CPP $)^{24}$ para aqueles depoentes que apresentam diversos tipos de dificuldades para falar em juízo. Nos casos específicos das audiências com as crianças e os adolescentes, tanto vítimas quanto testemunhas, estudos demonstram que a chave é assegurar a justiça e, ao mesmo tempo, evitar a revitimização da criança ${ }^{7}$.

A entrevista do DA é percebida como um meio mais eficaz de se chegar à prova:

O objetivo é chegar mais próximo possível de um relato fidedigno, com menos prejuizo emocional. (S 02)
Ao se considerar a necessidade da tomada do depoimento das crianças e dos adolescentes, com o desenvolvimento das metodologias de inquirição, na atualidade se tenta maximizar a eficácia da tomada do depoimento, enquanto produção de prova, ao mesmo tempo que se busca minimizar os possíveis danos causados por esse procedimento $^{8,10-12,25}$.

Estudos apontam a importância da participação das crianças e dos adolescentes no processo judicial, entendendo-as na sua condição de sujeitos de direito ${ }^{5,10}$. Entretanto, também se considera que, na audiência, as crianças e os adolescentes não são respeitados em sua condição de sujeitos, sendo transformados em objetos do processo judicial ${ }^{12,14,15}$. E, ainda, que o emprego da técnica de inquirição, contida no substitutivo ao Projeto de Lei n. 4.126, de 2004, não garante às crianças e aos adolescentes o direito à opinião e considera que a inquirição parte de uma concepção utilitária da obtenção da informação, voltada à produção de prova em processo judicial ${ }^{14}$.

$\mathrm{Na}$ visão dos sujeitos, o DA favorece a produção de provas, facilitando o processo de responsabilização do agressor:

A técnica da entrevista traz qualidade e quantidade. A gente tem um grande número de informações de detalhes. Por não conter perguntas fechadas, eu acho que contribui bastante. (S 05)

Hoje os culpados estão sendo condenados por causa do relato de crianças, o que é um avanço. (S 08)

Vários modos de tornar o depoimento de crianças menos traumático têm sido discutidos em pesquisas científicas, que mostram que as práticas judiciais específicas podem maximizar a veracidade do testemunho e reduzir a revitimização ${ }^{17,18}$. Tal maximização, e seus componentes, podem afetar crianças envolvidas em processos judiciais. Neste vértice, uma possível vantagem da técnica da tomada do depoimento está em assegurar a justiça ao mesmo tempo que evita a revitimização.

A adoção de metodologias específicas promoveu mudanças em vários países, ao proporcionar maior clarificação e contribuir para um maior número de condenações ${ }^{18}$. Na percepção dos sujeitos, a entrevista do DA tem contribuído para a condenação dos culpados. Entretanto, não encontramos estudos que abordem, na realidade brasileira, o desfecho dos processos de acordo com a adoção de metodologias para a tomada do depoimento das crianças e dos adolescentes vítimas ou testemunhas de violência. 


\section{Proteção}

A percepção do DA como instrumento de proteção às crianças e adolescentes é evidenciada em falas:

O depoimento acolhedor veio proporcionar pra crianças e adolescentes um espaço emocional favorável, pra que possam, através de uma técnica apropriada, resgatar fatos traumáticos, e através da habilidade do entrevistador, poder expor de forma clara e objetiva, pra que o relato dela tenha o valor que deve ter. (S 08 )

A despeito das peculiaridades das crianças e dos adolescentes, suas necessidades não eram consideradas nos procedimentos judiciais e as normas brasileiras para sua audiência em juízo eram as mesmas utilizadas com os adultos até pouco tempo atrás ${ }^{15}$.

Para que as crianças e os adolescentes possam se expressar em juízo deve haver uma escuta sensível e empática, visando ao conhecimento da sua experiência ${ }^{24}$. É indispensável um espaço de escuta que preserve o direito das crianças e adolescentes, como de ser ouvidos em situação que lhes garanta, conforme determinação do $\mathrm{ECA}^{20}$, o tratamento baseado na compreensão da sua condição de pessoas em desenvolvimento.

A condição de pessoa em desenvolvimento também é abordada ao se questionar o grau de responsabilidade jurídica atribuído às crianças e adolescentes. É delegada a eles a tarefa de produzir provas que podem levar à condenação do acusado, que pode ser um familiar ${ }^{24}$.

A entrevista, em seus detalhes, é percebida como uma técnica que contribui para a proteção ao depoente:

Durante a entrevista, a gente tenta colher os pontos principais: o que aconteceu, como aconteceu, com quem, e quando foi. Se busca uma amostra geral do evento e as perguntas dão clarificação e servem pra assistente social, pra psicóloga e pro juiz. Não há necessidade de ouvir a criança novamente. (S 07)

Os pontos referidos pelo sujeito constam no art. 201 do CPP e buscam a obtenção das informações necessárias à decisão da causa ${ }^{23}$. Desse modo, o DA, ao mesmo tempo que cumpre os passos previstos no CPP, busca minimizar as dificuldades identificadas na audiência tradicional. Observa-se que no Judiciário se utiliza um conjunto de medidas que visam à objetividade e à solução do problema, constituindo-se em experiência difícil para as crianças, que estão em desenvolvimento ${ }^{24}$.

De acordo com a técnica da entrevista do DA, o depoimento é gravado e anexado ao processo e a gravação vale como prova no decorrer de todo o processo, não sendo necessário repetir o depoimento em juízo ${ }^{6}$.

O fato de o depoimento ocorrer uma só vez é apontado como estratégia de prevenção à revitimização, considerando que falar sobre a violência sofrida leva a vítima a revivê-la ${ }^{9,16,18}$. Contudo, também se discute que nesses casos não se respeita o tempo da criança ou adolescente, pois as vítimas de violência sexual, em geral, têm dificuldades para falar sobre o assunto, necessitando, por vezes, de mais de uma oportunidade para fazer o relato ${ }^{11}$.

A entrevista é colocada como um instrumento de proteção às vítimas, de acordo com a fala a seguir:

Com o depoimento acolhedor, quando a criança ou adolescente é entrevistada, ela fica numa sala separada, não fica exposta aos diversos atores processuais, e isso resguarda muito o emocional dela. (S 06)

A estrutura física da central do depoimento acolhedor é composta de três salas: uma para a coordenação dos trabalhos técnicos e administrativos, uma para a entrevista e outra para a audiência ${ }^{6}$. A entrevista é transmitida por meio de um sistema de áudio e vídeo simultaneamente para a sala de audiência, onde ficam o magistrado, o promotor público, o defensor e o acusado. Desse modo, a vítima dá seu testemunho sem ter de passar pelo constrangimento de encarar o acusado $^{17}$.

A sala destinada à entrevista foi ambientada para acolher crianças e adolescentes, com decoração amena e neutra para não distrair o depoente, permanecendo apenas a criança/adolescente e o entrevistador. Em casos especiais o juiz permite a permanência de um responsável, que se sentará numa poltrona disposta em local que não possa ser visto diretamente pela criança para que não haja interferência no depoimento ${ }^{6}$. Baseada nos estudos da psicologia do testemunho, a entrevista é composta das fases de planejamento e preparação, engajamento e explicação, relato e clarificação, fechamento e avaliação. Após o relato livre e das perguntas do entrevistador para clarificação, o juiz formula perguntas, transmitidas ao entrevistador por meio de ponto eletrônico. Por sua vez, o entrevistador transmite a pergunta para a criança /ou adolescente, reformulando-as, visando a não revitimização ou a adequação para a compreensão do depoente ${ }^{18}$.

Os sujeitos percebem que a entrevista investigativa pode contemplar mais que a produção de provas, ao mostrar que durante sua realiza- 
ção também podem ser identificadas necessidades das crianças e dos adolescentes:

$\mathrm{Na}$ entrevista, se identificarem a necessidade do encaminhamento, os entrevistadores recorrem à equipe da Central, que faz os encaminhamentos. Tem que fazer a última etapa, que é o fechamento. (S 03)

Os danos decorrentes da violência sexual podem resultar na necessidade de atendimento imediato, de médio e longo prazo, devendo haver o empenho para a proteção às vítimas por meio de medidas interdisciplinares e em rede $\mathrm{e}^{2,14}$. São recomendadas articulações com instituições de saúde, de educação, de assistência social, centros de defesa de direitos, universidades, dentre outras, com o objetivo de realizar o atendimento às víti$\operatorname{mas}^{1,8,20,26}$.

Ao se considerar a violência sexual contra crianças e adolescentes em sua complexidade, as ações devem ser realizadas por uma rede organizada, que valorize as reais necessidades, sendo a articulação entre serviços de vários setores uma condição necessária para a proteção integral às vítimas $^{1,2,8,26,27}$. Especialmente os serviços de saúde mental devem ser articulados como uma retaguarda imediata para encaminhamento da vítima e da sua família' ${ }^{1,2,8}$.

\section{Desafios/necessidades}

A entrevista do DA também é percebida como um avanço para a sociedade como um todo, e como um projeto novo, sendo um desafio para todos:

É um projeto novo pra todo mundo, novo para o Tribunal, para a instituição, pra nós, entrevistadores, pro juiz, defensores, promotores. (S 05)

Semelhante em alguns aspectos ao projeto do DSD, o DA é a primeira experiência no estado de Pernambuco, no âmbito do Poder Judiciário, demandando ampla discussão sobre a prevenção da revitimização das crianças e adolescentes nos processos judiciais.

A obtenção do testemunho de crianças e adolescentes é um tema polêmico, tendo acarretado debates calorosos. Na trajetória da implantação do depoimento especial no Brasil, nem sempre foi possível equacionar as funções do cargo de analista judiciário com as atribuições dos assistentes sociais e psicólogos, contidas nas leis do exercício profissional. Constata-se que a inquirição da vítima é considerada pelos Conselhos de Psicologia e de Serviço Social uma atribuição exclusiva dos juízes, que, ao invés de delegar a atividade, deveriam se qualificar para realizá-la $a^{1,28,29}$. Além das questões referentes às atribuições de cada categoria profissional, observa-se que propostas novas, em geral, acarretam incertezas e ansiedade. As adaptações se dão na esfera pessoal, social e institucional, evidenciando as dificuldades para lidar com o novo ${ }^{25}$.

A efetivação da nova prática no serviço estudado enfrenta dificuldades, entre outras causas, devido à estrutura e à dinâmica existentes no Poder Judiciário brasileiro, como observado na fala a seguir:

Há um espaço de dois, três, quatro anos do fato pra ouvida. É muito difícil pra criança e se afasta do objetivo principal do depoimento acolhedor. Muitas vezes, além dela ter falado várias vezes sobre o fato, quando chega no judiciário ela vai falar de novo. (S 06)

Os processos judiciais em geral levam cerca de cinco anos para sua conclusão ${ }^{27}$. A morosidade dos trâmites processuais expõe a criança/o adolescente e seus familiares aos procedimentos judiciais por longo tempo, impedindo que os envolvidos no processo retomem suas vidas ${ }^{28}$. Até que seja encerrado o processo, em muitos casos, a criança ou o adolescente continua em contato com o acusado e as vítimas e suas famílias passam a ser desacreditadas pela comunidade ou pela família estendida. A morosidade resulta em arquivamento de processos ou declaração de inocência do autor da violência, por falta de provas, sendo um indicativo da ineficiência do Poder Judiciário ${ }^{1,27}$.

Os vários anos de tramitação dos processos que envolvem crianças e adolescentes demonstram que o princípio da proteção integral não é respeitado também no Poder Judiciário. O ECA, em seu art. 152, assegura que "aos procedimentos regulados nesta Lei aplicam-se subsidiariamente as normas gerais previstas na legislação processual pertinente", e, ao mesmo tempo, no parágrafo único desse artigo, assegura "sob pena de responsabilidade, prioridade absoluta na tramitação dos processos e procedimentos previstos nesta Lei, assim como na execução dos atos e diligências a eles referentes" ${ }^{20}$. É importante mencionar que a prioridade absoluta se deve à identificação das crianças e dos adolescentes como vulneráveis, por serem indivíduos ainda imaturos para enfrentar as exigências do ambiente, o que tem sido importante para a definição de ações para melhorar a qualidade de vida desses grupos etários ${ }^{21}$.

A criança deve ser ouvida uma só vez e em momento mais próximo à notificação, entretanto, no estado de Pernambuco, como em outros estados brasileiros, ainda se verifica que "a crian- 
ça é ouvida entre três a seis vezes desde a notificação/denúncia do fato delituoso, por instituições como Conselho Tutelar, delegacia especializada, Instituto Médico Legal"18.

A estrutura do serviço e a relação entre as equipes são percebidas pelos sujeitos como fatores dificultadores:

[...] por problema da secretaria a criança não veio, o réu não foi intimado. (S 08)

Se a gente conseguisse mais essa sintonia entre os operadores do direito e o entrevistador [...]. (S 05)

A diversidade de formação dos profissionais que atuam nos processos, somada a outras questões, como da estrutura do Poder Judiciário, evidenciam o conflito entre a cultura penal e o direito novo, aquele baseado nos princípios da proteção integral e da prioridade absoluta ${ }^{16}$. Entretanto, são necessárias adaptações do Poder Judiciário para a realização da escuta da criança, que deve ser operacionalizada por diversas áreas do conhecimento e ocorrer em sintonia, de modo $\operatorname{articulado}^{25}$.

A violência sofrida gera impacto na vítima, assim como o longo tempo decorrido entre a denúncia e a designação da criança para sua oitiva, situações gera ansiedade ${ }^{25}$. A expectativa e a ansiedade experimentadas pelas crianças e adolescentes quando são chamadas para dar seu depoimento podem prolongar-se, caso a audiência atrase, ou, o pior, seja adiada. Por isso, devem atuar em sintonia os entrevistadores, os operadores do direito e as pessoas envolvidas nos trabalhos cartoriais, de modo a garantir a celeridade desses processos.

Outras dificuldades percebidas pelos sujeitos se referem a necessidades que extrapolam os procedimentos judiciais:

A família tem que sair com um encaminhamento. A família tá precisando de intervenção psicológica, social, deve ser marcada. Quando o encaminhamento não acontece, a criança perde muito. (S 01)

$\mathrm{O}$ atendimento necessário às crianças e aos adolescentes está previsto no ECA, art. 87, III, que prevê serviços especiais de prevenção e atendimento médico e psicossocial às vítimas de negligência, maus-tratos, exploração, abuso, crueldade e opressão. Além disso, o inciso V do mesmo artigo prevê a proteção jurídico-social por entidades de defesa dos direitos da criança e do adolescente ${ }^{20}$.

Crítica ao DSD refere que este ocorre apenas com o intuito da obtenção de provas jurídicas contra o acusado, não contemplando as necessi- dades das crianças e dos adolescentes ${ }^{30}$. Tais críticas se fundamentam na afirmação de que o Estado, na busca da responsabilização do agressor, canaliza muitos recursos tecnológicos para essa finalidade, não ocorrendo o mesmo empenho no sentido de minimizar os danos decorrentes das violências perpetradas ${ }^{14}$.

Os sujeitos demonstram uma percepção positiva da entrevista do DA, enquanto uma técnica eficaz em relação aos seus objetivos. Entretanto, verifica-se que seu processo metodológico envolve vários aspectos que estão ligados à dinâmica de toda equipe e que, muitas vezes, estão sujeitos ao surgimento de situações externas que interferem na execução da técnica:

Existe uma lógica por trás da entrevista, com gravação, filmagem, e todo o equipamento deve estar pronto. [...] estando pronto, o entrevistado deve começar a relatar, e tem que ser naquele momento, porque depois perde a motivação inicial. Também escolher o melhor horário, pois se a pessoa está com fome, e aí compromete a disposição física pra contribuir. (S 02)

O grupo do outro lado, o juiz, o promotor, o defensor deve tá pontualmente na audiência. (S 01)

Os sujeitos percebem a atuação da Central do DA em interdependência com outras equipes do CICA. Para que sejam cumpridos todos os passos previstos na metodologia, outras equipes devem estar em sintonia com a audiência.

A entrevista realizada pela equipe do DA requer uma sequência de procedimentos com um encadeamento dinâmico. Ao mesmo tempo em que devem ser respeitados o ritmo e as necessidades da criança, esta precisa ser acolhida e motivada para fazer seu relato. O comportamento do entrevistador no decorrer da entrevista é regulado pelas atitudes da criança ${ }^{18} \mathrm{~A}$ criança ou o adolescente deve ser preparada(o) para a entrevista e o atraso da audiência prejudica essa preparação ${ }^{25}$, além de acentuar o estresse e o sentimento de desrespeito manifestado por crianças e adolescentes que depõem em juízo ${ }^{12}$.

Outro aspecto percebido pelos sujeitos como uma dificuldade para a proteção foi a não existência do espaço que deve ser reservado às crianças e adolescentes antes e após a audiência:

Tem que ter um espaço pra ela. A gente pode utilizar o espaço da equipe interprofissional que atua nas Varas de Crimes, mas ainda não é como deveria acontecer: ter um espaço ali distinto. (S 03)

Em estudo realizado no campo desta pesquisa constatou-se que o prédio tem entrada única, assim como os espaços para espera, que são cadeiras conjugadas localizadas nos corredores, 
próximas às salas de audiência. Não existiam dependências separadas para as vítimas e os acusados, ocorrendo, muitas vezes, a permanência de ambos no mesmo espaço, situação esta geradora de ansiedade para as crianças, adolescentes e seus familiares e ainda referida como motivo de faltas às audiências ${ }^{1}$.

Só recentemente o CPP, em alteração de 2008, contemplou a necessidade de a vítima ser preservada do encontro com o acusado nas dependências do Poder Judiciário. No art. 201, IV, consta: "Antes do início da audiência e durante a sua realização, será reservado espaço separado para o ofendido" 24 .

Observa-se que há um empenho no sentido de que as crianças e os adolescentes permaneçam no espaço da equipe interprofissional que atua nas Varas. Contudo, o próprio sujeito afirma não ser o espaço ideal, verificando-se que, apesar do esforço dos seus membros, o CICA ainda não dispõe de estrutura específica para tal finalidade.

Mesmo com todas as dificuldades e necessidades relatadas pelos sujeitos, observa-se que eles valorizam sua atuação como entrevistadores:

Quem dá vida e dá corpo à técnica é quem vai aplicar. Mas pra dar essa vida, questões básicas, não só do ambiente, mas da pessoa que vai aplicar, têm que ser satisfeitas. (S 02)

O que nos falta seria o acompanhamento psicológico, tipo uma supervisão. Tem entrevista que demora um, dois dias pra esquecer, porque é muito forte. Eu acredito que toda essa equipe precisa de acompanhamento. (S 07)

O entrevistador se depara com vários desafios da condução de entrevistas com crianças e adolescentes no âmbito jurídico. Essa atividade requer o domínio sobre as principais técnicas de entrevistas utilizadas para esses grupos etários, além do autoconhecimento e a capacidade de avaliar continuamente o seu desempenho ${ }^{18}$.

A supervisão técnica na área psicossocial no âmbito da Justiça pode articular o envolvimento e a subjetividade dos profissionais perante impasses ou problemas no desenvolvimento do trabalho, combinando a crítica com a efetividade/ eficácia da ação. O emprego da supervisão possibilita a discussão de dificuldades da estrutura do serviço e das relações entre seus membros, levando à exposição de seus problemas ${ }^{30}$.

Por sua vez, a supervisão psicológica é uma oportunidade de escutar o trabalhador em relação ao seu sofrimento. Os entrevistadores se deparam com vários fatores estressores em seu cotidiano. A consideração do sofrimento da criança; o contato com outros atores no processo, que nem sempre têm uma atitude protetora para com a vítima; o lidar com situações revitimizantes nas quais não pode interferir são alguns aspectos geradores de sofrimento ${ }^{31}$. Desse modo, o depoimento das crianças e dos adolescentes vítimas de violência sexual mostra-se como questão de saúde mental, ao se considerar como objeto de cuidados, tanto os entrevistados quanto os entrevistadores.

Os sujeitos mencionam a necessidade da formação continuada dos entrevistadores e da capacitação dos operadores do direito para a compreensão das questões relacionadas às crianças e aos adolescentes em sua condição de vulneráveis e à dinâmica da violência sexual intrafamiliar.

Precisaria de capacitações [cursos] dos entrevistadores. Também do pessoal do direito, pra que entendam a técnica e a questão da proteção integral à criança. No Código de Processo Penal diz que perguntas constrangedoras, vexatórias, o juiz pode cortar. Mas precisa capacitação pra entender o que é constrangedor, vexatório, que tá atribuindo culpa à vítima. (S 03)

Profissionais de várias formações referem limitações e falta de preparo para lidar com as crianças e os adolescentes em situação de violência sexual e afirmam que somente a formação universitária de base, ou seja, o curso de graduação, não é suficiente ${ }^{6,15,16}$. Em geral, por não conhecerem a dinâmica da violência sexual intrafamiliar e por terem dificuldades inconscientes com o tema, não encontram o modo adequado de se expressar no momento de formular as perguntas ${ }^{2}$.

Os entrevistadores necessitam de treinamentos frequentes, já que em alguns aspectos seu desempenho declina três meses após se efetivar a capacitação. Além disso, a continuação da aprendizagem no local de trabalho é limitada, mostrando-se uma barreira para o desenvolvimento da competência dos entrevistadores ${ }^{10}$.

As perguntas constrangedoras e vexatórias são circunstâncias que contrariam o princípio da proteção integral. A proteção a essas situações consta no ECA, em seu art. 18, que atribui a todos o dever de velar pela dignidade da criança e do adolescente, pondo-os a salvo de qualquer tratamento desumano, violento, aterrorizante, vexatório ou constrangedor ${ }^{20}$.

Os vários fatores relacionados à formação profissional, somados às estratégias dos defensores do réu para desqualificar o relato da vítima, levam o desrespeito ao CPP, que recomenda que sejam evitadas situações vexatórias e constrangedoras para a vítima ${ }^{15,25}$. Experiências internacionais mostram progressos na abordagem do problema. Observa-se que temas como a di- 
nâmica do abuso sexual e a perícia são discutidas em cursos sobre crimes sexuais contra crianças e adolescentes, assim como a entrevista forense e a vitimologia, mostrando que, além dos entrevistadores, os juízes, os promotores e os defensores também devem receber treinamento ${ }^{6}$.

As peculiaridades da entrevista de depoimento acolhedor podem estar relacionadas à limitação na comparabilidade dos dados deste estudo. Entretanto, em que pesem esses limites, acreditase que as maiores dificuldades são as decorrentes das características próprias do Poder Judiciário, enquanto instituição fechada e com uma tradição arraigada, e que situações semelhantes possivelmente ocorram em outros estados brasileiros.

\section{Considerações finais}

Em todos os temas que surgiram neste estudo, observou-se que os sujeitos demonstram uma percepção positiva da entrevista do depoimento acolhedor, enquanto instrumento de produção de prova e de proteção às crianças e aos adolescentes em sua condição de pessoas em desenvolvimento.

A cultura presente no Poder Judiciário se apresenta como obstáculo para a realização da entre-

\section{Colaboradores}

LMP Silva e MGC Ferriani trabalharam na concepção, coleta e análise de dados e redação final do artigo. EMST Roque trabalhou na análise de dados e redação e revisão final do artigo. MA Beserra e DM Carlos trabalharam na redação e revisão final do artigo. vista do depoimento acolhedor, sendo necessária a adaptação do TJPE para a efetivação da metodologia. Melhorias na estrutura física e o aprimoramento dos serventuários da Justiça envolvidos direta ou indiretamente na tomada do depoimento, revelam-se desafios a ser enfrentados para a implementação da entrevista do DA como um dos procedimentos dos processos judiciais que envolvem crianças e adolescentes vítimas ou testemunhas.

Outros estudos sobre o tema são necessários, para que os métodos de inquirição sejam aprimorados por meio de consistente fundamentação científica, devendo-se abordar: a) a efetividade dos métodos de inquirição, enquanto produção de provas, por meio do estudo sobre o desfecho dos processos conforme a utilização das metodologias adotadas; b) a efetividade da proteção às crianças e aos adolescentes inquiridos por meio das diversas técnicas.

Considera-se que com base no conhecimento com sólidos fundamentos científicos se poderá promover mudanças na realidade do sistema judicial brasileiro, levando a uma abordagem das crianças e dos adolescentes fundamentada nos princípios da proteção integral.

\section{Referências}

1. Silva LMP, Ferriani MGC, Silva MAI. O Poder Judiciário como última instância de proteção às crianças e aos adolescentes: ações intersetoriais, investimento em recursos humanos e estruturação dos serviços. Rev Latino-Am Enferm 2012; 20(3):444-452.

2. Fürniss T. Abuso sexual da criança: uma abordagem multidisciplinar. Porto Alegre: Artes Médicas; 1993.

3. Granjeiro IACL, Costa LF. O estudo psicossocial forense como subsídio para a decisão judicial na situação de abuso sexual. Psicol Teor Pesqui 2008; 24(2):161-169.

4. Roque EMST, Ferriani MGC, Silva MAI. Intrafamily violence and justice. Rev Latino-Am Enferm 2008; 16(5):908-914.

5. Balbinotti C. A violência sexual infantil intrafamiliar: a revitimização da criança e do adolescente vítimas de abuso. Porto Alegre: PUCRS; [s.n.]; 2008. [acessado 2010 jun 12]. Disponível em: http://www3. pucrs.br/pucrs/files/uni/poa/direito/graduacao/tcc/ tcc2/trabalhos2008_1/claudia_balbinotti.pdf. 
6. Childhood, pela proteção da infância. Depoimento acolhedor: salas especiais oferecem investigação judicial mais digna para crianças e adolescentes vítimas de violência. São Paulo: Childhood; 2010. [acessado 2011 fev 18]. Disponível em: http://www. childhood.org.br/depoimento-acolhedor-salasespeciais-oferecem-investigacao-judicial-mais-dignapara-criancas-e-adolescentes-vitimas-de-violencia

7. Cezar JAD. Depoimento sem dano: uma alternativa para inquirir crianças e adolescentes nos processos judiciais. Porto Alegre: Livraria do Advogado; 2007.

8. World Health Organization (WHO). Guidelines for medico-legal care for victims of sexual violence. Geneva: WHO; 2003.

9. Cyr M, Lamb ME. Assessing the effectiveness of the NICHD investigative interview protocol when interviewing French-speaking alleged victims of child sexual abuse in Quebec. Child Abuse Negl 2009; 33(5):257-268.

10. Powell MB, Fisher RP, Hughes-Sholes CH. The effect of using trained versus untrained adult respondents in simulated practice interviews about child abuse. Child Abuse Negl 2008; 32(11):1007-1016.

11. Patterson T, Pipe ME. Exploratory assessments of child abuse: children's responses to interviewer's questions across multiple interview sessions. Child Abuse Negl 2009; 33(8):490-504

12. Back C, Gustafsson PA, Larsson I, Berterö C. Managing the proceedings: an interpretative phenome nological analysis of sexual abused children's experience with the legal process. Child Abuse Negl 2011; 35(1):50-57.

13. Granjeiro IACL, Costa LF. O estudo psicossocial forense como subsídio para a decisão judicial na situação de abuso sexual. Psicol Teor Pesqui 2008; 24(2):161-169.

14. Aleixo KC. A extração da verdade e as técnicas inquisitórias voltadas para a criança e o adolescente. Psicol Clin 2008; 20(2):103-111.

15. Fröner JP, Ramires VRR. A escuta de crianças vítimas de abuso sexual intrafamiliar na concepção de profissionais que atuam no âmbito do Judiciário. Psicol Rev 2009; 15(3):60-81.

16. Hoffmeister MV. Tomada de depoimento especial de crianças e adolescentes em situação de abuso sexual desafios à intervenção profissional do assistente social na perspectiva da garantia de direitos [dissertação]. Porto Alegre (RS): Pontifícia Universidade Católica do Rio Grande do Sul; 2012.

17. Childhood Brasil. Childhood, pela proteção da infância. Juiz da Infância e Juventude de Pernambuco diz que depoimento de crianças em sala especial ajuda a acabar com a impunidade. São Paulo: Childhood; 2010. [acessado 2010 abr 30]. Disponível em: http:// www.childhood.org.br/juiz-da-infancia-e-juventudede-pernambuco-diz-que-depoimento-de-criancasem-sala-especial-ajuda-a-acabar-com-a-impunidade.
18. Brasil. Desafios da oitiva de criancas no âmbito forense. Brasília: Secretaria Especial dos Direitos Humanos; 2009.

19. Brasil. Recomendação n. 33 , de 23 de novembro de 2010: recomenda aos tribunais a criação de serviços especializados para escuta de crianças e adolescentes vítimas ou testemunhas de violência nos processos judiciais. Depoimento especial. Brasília: Conselho Nacional de Justiça; 2010.

20. Brasil. Lei n. 8.069, de 13 de julho de 1990: dispõe sobre o Estatuto da Criança e do Adolescente e dá outras providências. Diário Oficial da União 1990; 16 jul.

21. Costa ACG. Natureza e implantação do novo direito da criança e do adolescente. In: Pereira TS, coordenador. Estatuto da criança e do adolescente: Lei 8.069/90 - estudos sócio-jurídicos. Rio de Janeiro: Renovar; 1992.

22. Bardin L. Análise de conteúdo. Lisboa: Ed. 70; 2008

23. Brasil. Ministério da Saúde. Conselho Nacional de Saúde. Resolução no. 196 de 10 de outubro de 1996. Diretrizes e Normas Regulamentadoras de Pesquisas Envolvendo Seres Humanos. Diário Oficial da União 1996; 16 out.

24. Brasil. Decreto-Lei n. 3.689, de 3 de outubro de 1941: Código de Processo Penal. Diário Oficial da União 1941; 13 out.

25. Fröner JP, Ramires VRR. Escuta de crianças vítimas de abuso sexual no âmbito jurídico: uma revisão crítica da literatura. Paideia 2008; 18(40):267-278.

26. Paixão ACW, Deslandes SF. Abuso sexual infantojuvenil: ações municipais da saúde para a garantia do atendimento. Cien Saude Colet 2011; 16(10):4189-4198.

27. Martins CBG, Jorge MHPM. Desfecho dos casos de violência contra crianças e adolescentes no poder judiciário. Acta Paul Enferm 2009; 22(6):800-807.

28. Costa LF, Penso MA, Legnani VN, Sudbrack MFO. As competências da psicologia jurídica na avaliação psicossocial de famílias em conflito. Psicol Soc 2009; 21(2):233-241.

29. Brito LMT. Diga-me agora. O depoimento sem dano em análise. Psicol Clin 2009; 20(2):113-125.

30. Faleiros VP. Uma experiência de supervisão na área psicossocial: desafios teórico-práticos. Revista $\mathrm{Ka}$ tálysis 2009; 12(2):258-267.

31. Ribeiro R, Costa LF. As emoções do profissional psicossocial frente à situação de abuso sexual infantil. Estilos Clín 2007; 12(23):130-147.

Artigo apresentado em 19/08/2012

Aprovado em 24/02/2013

Versão final apresentada em 06/03/2013 